\title{
Performance of Permeable Pavement with Subsurface Micro Detention Storage as Rainwater Harvesting Device
}

\author{
Norazlina Bateni ${ }^{1(\bowtie)}$, Lai Sai Hin ${ }^{2}$, Md Abdul Mannan ${ }^{1}$, \\ Jethro Henry Adam ${ }^{1}$, Kuryati Kipli ${ }^{1}$, and Rosmina Ahmad Bustami ${ }^{1}$ \\ ${ }^{1}$ Faculty of Engineering, Universiti Malaysia Sarawak, Kota Samarahan, \\ Sarawak, Malaysia \\ \{bnorazlina, mamannan, hajethro, kkuryati, \\ abrosmina\}@unimas.my \\ ${ }^{2}$ Faculty of Engineering, Universiti Malaya, Kuala Lumpur, Malaysia \\ laish@um.my
}

\begin{abstract}
In this paper, permeable pavement, which is a sustainable infrastructure, is designed with subsurface micro detention pond storage, called, StormPav. The product is designed with a cylindrical hollow space of $70 \%$ void volume and occupied about $0.19 \mathrm{~m}^{3} / \mathrm{m}^{2}$ pavement area for rainwater harvesting device. The experimental investigations for application asa rainwater harvesting were conducted in the laboratory. The hydrology parameter variables examined included volume capacity at various rainfall intensities, volume parameters (water depth and applicable area) and system properties. A modelling simulation using Stormwater Management Model (SWMM) to verify laboratory results. A further simulation of a case study for various sizes of rain barrels was performed. The results showed that the product proved advantageous on a bigger space and volume of void content to provide for a rainwater harvesting system with a connected underground storage tank.
\end{abstract}

Keywords: Permeable pavement $\cdot$ Rainwater harvesting $\cdot$ Hydrological parameter $\cdot$ Infiltration-based $\cdot$ StormPav

\section{Introduction}

It is well-known that urbanisation comes with it a risk of disturbance on the hydrological cycle through the changes in rainfall-runoff volume and peakflow rate. The impact on the urbanisation continues to be an open problem that affects the community through flash flood and water quality degradation due to congestion of the stormwater drainage system. In the past, urban runoff is channelled to human-made concrete drainage structures to flow the water to the downstream river corridors [1]. In [2], such practices bring a flash flood to the adjacent areas due to rapid land development, which increases the surface runoff when intense rainstorms occurred. The appropriate mitigation measure of a stormwater management technique was applied to lessen the impact of high runoff volume and peak flowrate [3-5]. Rainwater Harvesting System (RWH) is one of the stormwater management techniques to address the issue of the 
Dear Prof/ AP/ Dr/ Sir and Madam,

Warm greetings from Department of Civil \& Environmental Engineering, Universiti Teknologi PETRONAS (UTP), Malaysia

First, on behalf of the organizing committee, we would like to thank you for the support in submitting papers to our conference. Also, we would like to congratulate you also on the paper acceptances.

As promised earlier that all accepted papers will be published to the SCOPUS indexed Lecture Notes in Civil Engineering (LNCE) by Springer, in this year 2020 itself. With that, we would like to update that based on the communication with Springer, this conference publication will be tentatively available by $28^{\text {th }}$ Dec 2020 .

We thank you for your patience and apologise for any inconvenience caused during this time of great uncertainty. We are confident that with all of your unwavering support, ESTCON and ICCOEE will be better, bigger and bolder! For more info or to contact us, please email to iccoee2020@utp.edu.my or visit to our website http://estcon.utp.edu.my/iccoee.

Conference Chair,

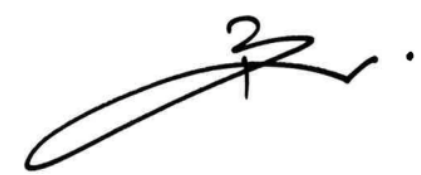

Assoc Prof Ir Dr Bashar S. Mohammed 


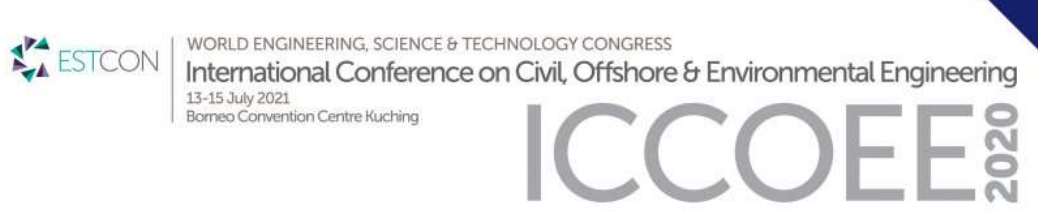

List of accepted papers from UNIMAS

\begin{tabular}{|l|l|}
\hline Corresponding Author & Paper ID \\
\hline Norazlina Bateni & 1570628922 \\
\hline Idawati Ismail & 1570635673 \\
\hline Yee Yong Lee & 1570635866 \\
\hline Sim Nee Ting & 1570637631 \\
\hline Ron Aldrino Chan & 1570637780 \\
\hline Mohammad Ibrahim Safawi bin Mohammad Zain & 1570646436 \\
\hline
\end{tabular}

